\title{
Search Frictions, Credit Market Liquidity, and Net Interest Margin Cyclicality
}

\author{
Kevin E. Beaubrun-Diant*and Fabien Tripier ${ }^{\dagger}$
}

October 23, 2013

\begin{abstract}
The present paper contributes to the body of knowledge on search frictions in credit markets by demonstrating their ability to explain why the net interest margins of banks behave countercyclically. During periods of expansion, a fall in the net interest margin proceeds from two mechanisms: $(i)$ lenders accept that they must finance entrepreneurs that have lower productivity and $(i i)$ the liquidity of the credit market rises, which simplifies access to loans for entrepreneurs and thereby reinforces their threat point when bargaining the interest rate of the loan.
\end{abstract}

Keywords: Search Friction; Matching Model; Nash Bargaining; Bank Interest Margin.

JEL Classification Codes: C78; E32; E44; G21

\section{Introduction}

During the two most recent recessions of 2001 and 2007-2009, the net interest margins of banks in the United States rose by approximately 20in under a year, whereas they steadily

\footnotetext{
* Corresponding author: Université Paris-Dauphine, LEDA-SDFi. Place du Maréchal de Lattre de Tassigny. 75775 Paris Cedex 16, France. Tel. (+33)1 4405 4719. Email: kevin.beaubrun@dauphine.fr.

${ }^{\dagger}$ University of Lille 1 (CLERSE) \& CEPII, Email: fabien.tripier@univ-lille.fr.
} 
declined during the expansion of 2002-2006. ${ }^{1}$ These figures illustrate the countercyclical behaviour of the net interest margin ${ }^{2}$, which is of considerable importance given the impact of interest rates on the profitability of banks, on macroeconomic activity, and on monetary policy. ${ }^{3}$ We herein provide a new theoretical explanation of this behaviour by investigating the possible effects of search frictions on the credit market.

Recent studies have used a search framework to explain the consequences of imperfections on the credit market in line with the approaches proposed by Den Haan et al. (2003) and Wasmer and Weil (2004). The premise of the research efforts of these authors is that new credit arrangements are not instantaneous, but are rather costly and time consuming. These constraints are mainly due to imperfect access to the information of agents. As a result, agents must spent time and resources meeting their counterpart's needs (e.g., finding a loan for entrepreneurs or finding an entrepreneur for banks). ${ }^{4} \mathrm{~A}$ key point in this literature is the powerful nature of the amplification and propagation mechanisms associated with matching friction on the credit market. While many authors have provided detailed analyses of the equilibrium amount of credit market quantities, they have not studied the dynamics of credit market prices, namely the interest rates and margins that ensue. ${ }^{5}$ This paper therefore contributes to the body of knowledge on credit market search by demonstrating the relevance of such a mechanism in accounting for the countercyclical behaviour of the net interest margin.

The model developed herein is in the spirit of the matching models presented by Diamond (1982), Mortensen and Pissarides (1994), and Pissarides (2000). ${ }^{6}$ The model proposed herein incorporates the following three components: $(i)$ an aggregate matching function that identifies the search-and-meet processes and then determines the flow of new matches as a function of the mass of unmatched entrepreneurs and the searching intensity of lenders; $(i i)$ a financial contract that determines the credit interest rate as an outcome of a Nash bargaining solution; and (iii) an endogenous separation process, which is the consequence of idiosyncratic shocks on the entrepreneur's technology production. ${ }^{7}$ By qualitatively analysing the model's equilibrium, we thus derive the theoretical conditions under which the net interest margin behaves countercyclically. Based on this analysis, 
our main theoretical result shows that the net interest margin's response to technological shocks is ambiguous because of the combination of the three antagonistic effects described briefly below.

Lenders and borrowers bargain to share the value of the match, which depends on the profits yielded by the production activity. As a positive improvement in the technological shock increases the returns on the production activity and therefore the associated profit, the lender can then negotiate a higher loan rate. This first effect widens the net interest margin during an expansion, but the influence of such widening may be outweighed by the other two effects. The second effect is related to the countercyclical behaviour of the separation rate. ${ }^{8}$ During an expansion, lenders and borrowers are less selective and accept matches that have a lower level of idiosyncratic productivity. As a result, average idiosyncratic productivity declines, the profits from the production activity decrease, and the net interest margin tightens. The third effect is a consequence of modifications to the external opportunities of entrepreneurs. For each agent, the ease of finding another partner determines its threat point and thus its raised revenues. A positive technological shock increases the expected value of future matches, which stimulates the supply of loans on the credit market. The relative abundance of liquidity ${ }^{9}$ shortens the average delay in finding a loan and thus reinforces the entrepreneur's threat point in the bargaining process. This phenomenon lowers the loan interest rate bargained by entrepreneurs and thus decreases the net interest margin. These qualitative results allow us to clarify the mechanisms at work and can be illustrated by carrying out a numerical analysis of the model. We propose a calibration of the model such that both the net interest margin and the separation rate are countercyclical and accompanied by persistent fluctuations in output.

The remainder of this article is organised as follows. In Section II, we present the stylised facts of interest and describe the empirical data used. The model economy is described in Section III. The equilibrium of the model is defined and studied in both an analytical and a numerical fashion in Section IV. A discussion of the theoretical literature is provided in Section II. Section VI concludes. 


\section{Some Statistics on the Net Interest Margin in the US}

In this section, we describe the cyclical behaviour of a bank's net interest margin. In line with Alliaga-Diaz and Olivero (2011) and Corbae and D'Erasmo (2013), we focus on US commercial banks and derive our data from the Consolidated Report of Condition and Income, which is available for all banks regulated by the Federal Reserve System, the Federal Deposit Insurance Corporation, and the Comptroller of the Currency. From this report, we compile a quarterly dataset that runs from 1985 to $2008 .{ }^{10}$ Moreover, we follow the approaches put forward by Kashyap and Stein (2000), Alliaga-Diaz and Olivero (2011), and Corbae and D'Erasmo (2013) by constructing consistent time series for our variables of interest. In the Data Appendix, we describe these variables and the data sources.

We use six definitions for our margins. Margins 1, 2, and 3 are all calculated as the difference between (i) the ratio of interest income on loans to the volume of loans and (ii) the ratio of interest expenses on deposits to the volume of deposits. As stated in Alliaga-Diaz and Olivero (2011), the main difference among these definitions is the way in which loan volume is adjusted for delinquent loans. ${ }^{11}$ Margins 4 and 5, derived from the FRED Database, are defined as the net interest margin for all US banks and the net interest margin for all US banks that have average assets under one billion dollars, respectively. Margin 6 is the only case in which macrodata used the spread between the bank prime and the three-month Treasury bill rates. As pointed out by Alliaga-Diaz and Olivero (2011) and Dueker and Thornton (1997), a change in the prime rate is indicative of a general shift in lending rates.

The historical series are shown in Figure 3 in the Appendix together with our proposed measure of the business cycle, namely real GDP per capita. The net interest margin series show substantial differences according to the definition of average values, volatilities, and historical evolution. This finding shows the importance of using different measures of the net interest margin to present robust empirical facts. To provide an insight into 
the countercyclical behaviour of the net interest margin, we also extract the cyclical components of GDP per capita and the net interest margin for the entire sample period.

\author{
"Table 1 here"
}

Table 1 presents the contemporaneous correlations with GDP, while Figure 4 illustrates the correlations at lead and lags $(k=-4$ to $k=4)$ with the associated confidence interval. Despite clear differences in the series, they all show significant countercyclical behaviour. The correlation coefficient ranges between -0.26 and -0.48 and is always nonzero at the $1 \%$ level (except for Margin 3 whose correlation with output is only nonzero at the 5\% level). Moreover, a significant negative correlation is still observed if we consider one lead or one lag for the margin. These values are consistent with the evidence presented by Aliaga-Diaz and Olivero (2011) and Corbae and D'Erasmo (2013).

\title{
III The Model Economy
}

Let us assume that the model economy is populated by two types of agents: entrepreneurs and financial intermediaries (lenders). Entrepreneurs specialise in project management and produce a unique final good. Our model assumes that entrepreneurs have no private wealth and use the lender's funds as the sole productive input. This assumption implies that production feasibility depends on the availability of the funds provided by lenders. In the same vein, the financial intermediary (or bank) is endowed with funds but has no skill to manage production projects.

Since the credit market is subject to search frictions, banks must pay a fixed search cost to find an entrepreneur on the market in a given period. A bank is only allowed to allocate its funds to an entrepreneur with whom it is currently matched. The bank must therefore form a bilateral long-term relationship with an entrepreneur. Once a lenderentrepreneur pair has been formed, a financial contract is agreed between these agents that determines the price of the funds lent by the bank.

The final good technology is subject to both an aggregate productivity shock and an idiosyncratic productivity shock. The amount of production, and thus the entrepreneur's 
ability to repay a debt, is therefore related to both these productivity levels. If the idiosyncratic productivity level is sufficiently high, then contracting in a given period will be solved according to a Nash bargaining solution. If not, both parties will agree to sever the relationship in order to avoid paying the fixed costs of production and loan management, and both agents will return to the credit market.

The following three subsections describe the model's key mechanisms in more detail: ( $i$ ) the matching function and search behaviours, (ii) idiosyncratic productivity shocks and the choice of the reservation productivity threshold, and (iii) the financial contract that determines the credit interest rate as an outcome of a Nash bargaining solution.

\section{The Matching Process}

Let $E$ be the population of entrepreneurs and let $N_{t}$ represent the number of entrepreneurs matched with lenders. The flow of new matches $M_{t}$ is a function of the numbers of unmatched entrepreneurs, $\left(E-N_{t}\right)$ and the lenders' loan supply, $V_{t}$. The search friction is summarised by an increasing and concave matching function $M_{t}=m\left(V_{t}, E-N_{t}\right)<$ $\min \left\{V_{t}, E_{t}-N_{t}\right\}$. The assumption of constant returns to scale for the matching technology leads to the following properties for matching probabilities:

(1) $\quad q_{t}=q\left(\theta_{t}\right)=\frac{p\left(\theta_{t}\right)}{\theta_{t}}=\frac{p_{t}}{\theta_{t}}$

Here, $q_{t}=M_{t} / V_{t}$ is the lender's matching probability, whereas $p_{t}=M_{t} /\left(E-N_{t}\right)$ is the matching probability for entrepreneurs. Importantly, $\theta_{t}=V_{t} /\left(E-N_{t}\right)$ represents credit market tightness. As $V_{t}$ increases, the tightness of the market also increases. $\theta_{t}$ could be interpreted as a liquidity index: in this context, the more lenders supply loans, the more liquid the market. ${ }^{12}$ In the remainder of this subsection, we assume a standard Cobb-Douglas matching function, with a scale parameter $\bar{m}>0$ and elasticity parameter $0<\chi<1$. Consequently, the matching probability for entrepreneurs is

(2) $p_{t}=\bar{m} \theta_{t}^{\chi}$ 
We define the law of motion of the rate of matched entrepreneurs, $n_{t}=N_{t} / E$, as follows:

$$
n_{t+1}=\left(1-s_{t+1}\right) \times\left[n_{t}+m\left(v_{t}, 1-n_{t}\right)\right],
$$

where $v_{t}=V_{t} / E$ and $s_{t}$ represent the endogenous rate of separation per period. The separation rate concerns both old matches, $n_{t}$, and new matches, $m_{t}$.

\section{Idiosyncratic Productivity Shocks and Reservation Produc- tivity}

Entrepreneurs are expected to undertake projects to produce $y_{t}$ units of the final good (the numeraire) according to the following constant returns to scale technology:

$$
y_{t}(\omega)=z_{t} \omega
$$

where $z_{t}$ is the aggregate productivity level and $\omega$ the idiosyncratic productivity level. The fixed amount of the loan is normalised to unity, without loss of generality. In each period, all entrepreneurs pick a new value for $\omega$ from the uniform distribution function $G(\omega)$ that satisfies $d G(\omega) / d \omega=1 /(\bar{\omega}-\underline{\omega})$, with $\bar{\omega}>\underline{\omega} . \omega$ is assumed to be perfectly observed by lenders.

Let $J_{t}(\omega)$ be the entrepreneur's value function of being matched with an idiosyncratic productivity level $\omega$. We have $J_{t}(\omega)=\max \left\{J_{t}^{a}(\omega), V_{t}^{e}\right\}$, where the entrepreneur that accepts the match obtains the value function $J_{t}^{a}(\omega)$. Otherwise, he or she turns to the credit market and then has the value function $V_{t}^{e}$. Reservation productivity is defined as the level $\widetilde{\omega}_{t}^{e}$ that satisfies the condition $J_{t}^{a}\left(\widetilde{\omega}_{t}^{e}\right)=V_{t}^{e}$ :

(4) $\max \left\{J_{t}^{a}(\omega), V_{t}^{e}\right\}=\left\{\begin{array}{l}J_{t}^{a}(\omega), \omega \geq \widetilde{\omega}_{t}^{e} \\ V_{t}^{e}, \omega<\widetilde{\omega}_{t}^{e}\end{array}\right.$

$\Pi_{t}(\omega)$, the value function for matched lenders, also depends on the idiosyncratic productivity of the entrepreneur's technology, $\omega: \Pi_{t}(\omega)=\max \left\{\Pi_{t}^{a}(\omega), V_{t}^{b}\right\}$. According 
to the realised value of $\omega$, a lender decides either to accept the match, in which case it obtains the value function $\Pi_{t}^{a}(\omega)$, or to refuse it, thereby obtaining $V_{t}^{b}$. For lenders, the reservation productivity level $\widetilde{\omega}_{t}^{b}$ satisfies the condition $\Pi_{t}^{a}\left(\widetilde{\omega}_{t}^{b}\right)=V_{t}^{b}$, with

(5) $\max \left\{\Pi_{t}^{a}(\omega), V_{t}^{b}\right\}=\left\{\begin{array}{l}\Pi_{t}^{a}\left(\omega_{t}\right), \omega \geq \widetilde{\omega}_{t}^{b} \\ V_{t}^{b}, \omega<\widetilde{\omega}_{t}^{b}\end{array}\right.$

Depending on the productivity of the project, matched lenders and entrepreneurs will decide either to pursue or to sever the credit relationship. If they choose to maintain cooperation, they will negotiate a financial contract in which a loan interest rate is determined.

\section{The Financial Agreement}

The financial contract determines the loan interest rate, $R_{t}^{\ell}(\omega)$, as a function of $\omega$, the idiosyncratic productivity of the entrepreneur's technology. The interest rate is the outcome of a Nash bargaining solution, where the respective bargaining power of the entrepreneur and lender are represented by $\eta$ and $(1-\eta)$. The use of this Nash bargaining solution leads to the traditional sharing rule:

$$
\eta\left(\Pi_{t}^{a}(\omega)-V_{t}^{b}\right)=(1-\eta)\left(J_{t}^{a}(\omega)-V_{t}^{e}\right)
$$

The outcome of the bargaining process ensures equality between the reservation productivity of the lender and that of the entrepreneur: $\widetilde{\omega}_{t}=\widetilde{\omega}_{t}^{e}=\widetilde{\omega}_{t}^{b}$. Indeed, the sharing rule (6) implies that the entrepreneur's payoff $\left(J_{t}^{a}(\omega)-V_{t}^{e}\right)$ is the share $(1 / \eta-1)^{-1}$ of the lender's payoff $\left(\Pi_{t}^{a}(\omega)-V_{t}^{b}\right)$. Therefore, for any $\omega$, if the lender wishes to pursue the relationship (which requires $\Pi_{t}^{a}(\omega)$ to be greater than or equal to $V_{t}^{b}$ ), this implies that the entrepreneur will also wish to stay matched. Therefore, the condition $J_{t}^{a}(\omega)>V_{t}^{e}$ must hold for entrepreneurs as well, and finally reservation productivity $\widetilde{\omega}_{t}$ must satisfy

$$
J_{t}^{a}\left(\widetilde{\omega}_{t}\right)-V_{t}^{e}=\frac{\eta}{1-\eta}\left(\Pi_{t}^{a}\left(\widetilde{\omega}_{t}\right)-V_{t}^{b}\right)=0
$$


For this value of reservation productivity $\widetilde{\omega}_{t}$, the separation rate is defined as

(8) $\quad s_{t}=\int_{\underline{\omega}}^{\widetilde{\omega}_{t}} d G(\omega)=\frac{\widetilde{\omega}_{t}-\underline{\omega}}{\bar{\omega}-\underline{\omega}}$

given the uniform distribution of $\omega$.

\section{Equilibrium Credit Cycle Properties}

This section discusses the credit cycle properties of the model presented in Section III. We first describe the theoretical properties and then use a numerical analysis to demonstrate the model's ability to reproduce the stylised facts. The full resolution of the model is presented in the Appendix. Subsection B defines the value functions introduced in the previous section, while Subsection C details the calculus for the equilibrium decisions concerning the entry, separation, and bargaining. Finally, the full equilibrium characterisation (definition, existence, and stability) is developed in Subsection D.

\section{Theoretical Results}

The topic of interest here is the cyclical characterisation of the net interest margin following a technological shock. Therefore, in the present paper, we define the equilibrium net interest margin to be the difference between the rate of return on a loan, $R_{t}^{\ell}(\omega)$, and the cost of the resources for the lender, $R^{h}$. To account for the heterogeneity of matches, the net interest margin is defined to be the average of the individual margins: ${ }^{13}$

(9) $\quad R_{t}^{p}=(1-\eta)\left[z_{t} \frac{\left(\bar{\omega}+\widetilde{\omega}_{t}\right)}{2}-x^{e}-R^{h}\right]+\eta\left(x^{b}-d \theta_{t}\right)$

Equation (9) is the weighted average of two terms whose coefficients represent the respective bargaining power of the agents $(1-\eta)$ and $\eta$. For $\eta=1$, which corresponds to the extreme case of the absence of bargaining power for the lender. The credit spread depends on two variables, namely the lender's cost, $x^{b}$, and credit market tightness, $\theta_{t}$. In the opposite case where $\eta=0$, entrepreneurs have no bargaining power and lenders earn 
the entire surplus from the production process, i.e., the average value of the production carried out by entrepreneurs, $z_{t}\left(\bar{\omega}+\widetilde{\omega}_{t}\right) / 2$, less the fixed cost of production, $x^{e}$, and less the interest paid to depositors, $R^{h}$.

The business cycle behaviour of an endogenous variable is characterised by its elasticity with respect to the technological shock, denoted $\alpha_{z}$, which satisfies $\widehat{\alpha}_{t}=\alpha_{z} \widehat{z}_{t}$, where $\widehat{\alpha}_{t}=\log \left(\alpha_{t} / \alpha\right)$ is the logdeviation of the variable $\alpha_{t}$, for $\alpha=\left\{R^{p}, \theta, \widetilde{\omega}\right\}$, and $\widehat{z}_{t}$ the logdeviation of the productivity shock. Based on this definition, the elasticity of the net interest margin with respect to the technological shock (see equation (D.14) in Appendix D) is

(10) $R^{p} R_{z}^{p}=(1-\eta)\left(\frac{\bar{\omega}+\widetilde{\omega}}{2}\right) z+(1-\eta) \frac{\widetilde{\omega}}{2} z \widetilde{\omega}_{z}-\eta d \theta \theta_{z}$

We now describe the conditions under which the net interest margin may behave countercyclically by analysing the sign of $R_{z}^{p}$. As shown by (10), the elasticity of the net interest margin to the technological shock is a function of the elasticities of credit market tightness, $\theta_{z}$, and of reservation productivity, $\widetilde{\omega}_{z}$. Therefore, we must first illustrate the link between the credit market tightness and the technological shock. We can then repeat the same exercise with reservation productivity.

Proposition 1 Credit market tightness is procyclical.

Proof. The elasticity of the credit market tightness to a technological shock (see equation (D.12) in Appendix D) is

(11) $\theta_{z}=\left(\frac{\rho_{z}}{1-\chi}\right)\left(\frac{\bar{\omega}+\widetilde{\omega}}{\bar{\omega}-\widetilde{\omega}}\right)\left[1-\frac{2 \theta d}{z(\bar{\omega}-\widetilde{\omega})}\left(\frac{1}{\bar{m} \theta^{\chi}}-\frac{\eta}{1-\chi}\right) \rho_{z}\right]^{-1}$

where $\theta_{z}$ is unambiguously positive, $\theta_{z}>0$, given the stability condition demonstrated in the proof of Proposition 5 (see Appendix D).

Credit market tightness responds positively to productivity shocks. Following a positive aggregate technological shock, lenders are willing to increase their search efforts on the credit market. Indeed, improvement in the entrepreneurs' technology signals higher 
productivity for the following periods. ${ }^{14}$ This mechanism is therefore clearly related to the persistent nature of shocks. The more persistent the productivity shock, the more positive is the credit market tightness. With no persistence, $\rho_{z}=0$, and the credit market tightness would become unambiguously acyclical.

Proposition 2 The separation rate is countercyclical if

(12) $\eta \leq(1-\chi)$

This is a sufficient (and not necessary) condition for a negative elasticity of the separation rate to a technological shock, namely $\widetilde{\omega}_{z}<0$.

Proof. The expression for the elasticity of reservation productivity to a technological shock is

$$
\widetilde{\omega}_{z}=-\left(\frac{1}{\bar{m} \theta^{\chi}}-\frac{\eta}{1-\chi}\right) \frac{(1-\chi) d \theta}{z \widetilde{\omega}} \theta_{z}-1
$$

as shown in equation (D.13) in Appendix D. Moreover, the case of $\widetilde{\omega}_{z}<0$ requires

$$
-\left(\frac{1}{\bar{m} \theta^{\chi}}-\frac{\eta}{1-\chi}\right) \frac{(1-\chi) d \theta}{z \widetilde{\omega}} \theta_{z}<1
$$

since $\theta_{z}>0$, a sufficient but not necessary condition of $\widetilde{\omega}_{z}<0$ is

$$
\frac{1}{\bar{m} \theta^{\chi}}>\frac{\eta}{1-\chi}
$$

which is necessarily satisfied under condition (12), because $\bar{m} \theta^{\chi}$ is the entrepreneur's matching probability and therefore below unity.

This condition (12) is always satisfied if the Hosios (1990) condition of efficiency holds, namely $\eta=(1-\chi)$. In this case, the trading externalities of the matching function are internalised in the Nash bargaining process given that the equilibrium reservation productivity depends on the technological shock via two mechanisms.

The first of these depends on the perfect substitutability of both aggregate and idio- 
syncratic productivity. In other words, a 1aggregate productivity leads to a 1productivity, because the separation is based on the overall level of the entrepreneur's productivity. ${ }^{15}$

The second mechanism by which a technological shock affects reservation productivity arises from the response to credit market tightness, which in turn affects reservation productivity $\widetilde{\omega}_{t}$ in two ways.

Firstly, the free entry condition states that the expected value of a match for lenders is equal to the average cost of a match: the higher the value of $\theta_{t}$, the higher the value of a match. In this case, lenders and entrepreneurs accept lower idiosyncratic productivity in order to preserve their current matches and, as a result, $\widetilde{\omega}_{t}$ decreases with $\theta_{t} \cdot{ }^{16}$

Secondly, as credit market tightness increases, better external opportunities emerge for entrepreneurs, who are therefore able to bargain lower interest rates from their partners. This bargaining process provokes a decline in the equilibrium bargained loan interest rate. In this way, high values of $\theta_{t}$ make lenders more selective and thereby increase the required reservation productivity level. In such a case, $\widetilde{\omega}_{t}$ increases with $\theta_{t} \cdot{ }^{17}$

From here, we assume that condition (12) is satisfied and we therefore examine the conditions of the countercyclical behaviour of the net interest margin.

Proposition 3 The net interest margin is countercyclical if

(13) $(1-\eta)\left(\frac{\bar{\omega}+\widetilde{\omega}}{2}\right) z<\eta d \theta \theta_{z}+(1-\eta) \frac{\widetilde{\omega}}{2} z\left(-\widetilde{\omega}_{z}\right)$

Under this condition, the elasticity of the net interest margin to a technological shock is negative, namely $R_{z}^{p}<0$.

Proof. This condition is deduced from the definition of $R_{z}^{p}$ in equation (10) and Propositions 1 and 2.

The elasticity of the net interest margin to a technological shock, $R_{z}^{p}$, allows us to assess whether this variable behaves countercyclically. The sign of $R_{z}^{p}$ depends on three components, each related to one of the following coefficients: $z, \widetilde{\omega}_{z}$, or $\theta_{z}$ (see Equation $(10))$.

This first effect leads to a procyclical net interest margin. A positive technological 
shock increases profits for the entrepreneur through a technological improvement (the coefficient of $z$ in Equation (10)). As the bargaining power of lender $(1-\eta)$ is higher, he or she may wish to take advantage of this in order to negotiate a higher loan interest rate. The size of this first effect thus depends on the lender's bargaining power and the average productivity of matches, namely $(\bar{\omega}+\widetilde{\omega}) z / 2$. The greater the bargaining power of the lender, the greater the appropriation of profit and the higher the impact of the technological shock on the net interest margin.

The second effect generates a countercyclical net interest margin related to the average productivity of matches (the coefficient of $\widetilde{\omega}_{z}$ in $(10)$ ). As reservation productivity $\widetilde{\omega}_{t}$ drops in response to a positive shock, the average productivity of matches reduces. The consequences for profits are the opposite of those of the first effect, leading therefore to a decrease in the net interest margin.

The third effect serves to generate a countercyclical net interest margin similar to the second. This effect is based on the threat point of entrepreneurs, which is influenced by credit market liquidity (the coefficient of $\theta_{z}$ in (10)). To understand which mechanism is at work, note that $\eta d \theta=p \times \eta \times(d / q)$, which implies that an entrepreneur can find another match, with a probability $p$, and obtain a share $\eta$ of the value of that match, $d / q$. Consequently, as the credit market tightens following a positive shock, better external opportunities present themselves to entrepreneurs, which significantly increases their threat point and tightens the net interest margin further.

To conclude, the second and third effects (the RHS term of (13)) must be sufficiently large to outweigh the first term (the LHS term of (13)) in order for the net interest margin to behave countercyclically. However, because the previous analysis of the equilibrium does not allow us to draw unambiguous conclusions about the model's ability to foster a countercyclical net interest margin, we now numerically simulate the model's solution in order to assess the plausibility of the presented theoretical model. 


\section{Numerical Analysis}

The previous theoretical analysis emphasised the interactions between the several mechanisms that determine the behaviour of the net interest margin. Some of the effects of a technological shock induce a procyclical net interest margin dynamic, whereas others lead to countercyclical behaviour. In what follows, we present numerical exercises carried out in order to assess and quantify the relative importance of these mechanisms according to the values of the structural parameters used in the present study.

\subsection{Calibration}

First, the model is calibrated by choosing the available empirical counterparts for the variables of interest. Because none of the previous variables allows us to calibrate all the structural parameters, we make additional assumptions about the values of these parameters.

We restrict their ranges using the conditions of the existence, uniqueness, and stability of the equilibrium. The unit of time is taken to be one quarter. The calibration constraints on interest rates are as follows. For our sample data, the quarterly interest rate on lender resources is $R^{h}=1.0204^{1 / 4}$ and the quarterly interest rate on loans is $R^{\ell}=1.0392^{1 / 4}$. Further, transition probabilities are fixed at the following values: $p=0.5, q=0.75$, and $s=1 / 16$. On average, it takes two quarters for an entrepreneur to find a lender and the lending relationship lasts four years. The condition of Hosios (1990) is imposed, namely $\chi=\eta=0.5$, and the scale parameters of the production and matching technologies are then set as follows: $\underline{\omega}=0.90, \bar{\omega}=1$, and $z=4$. Finally, the discount rate is set to a conventional value $\beta=0.995$. We then deduce from the steady-state restrictions the values of $\widetilde{\omega}, \theta, \bar{m}, d, x^{e}, x^{b}, n$, and $Y$. In the following subsection, we describe the business cycle behaviour of the model for this calibration.

\subsection{The Cyclical Behaviour of the Net Interest Margin}

We start the numerical analysis by describing the dynamic behaviour of the aggregate variables. Figure 5 depicts the impulse response functions (IRFs) to a positive technolog- 
ical shock on output, the net interest margin, and reservation productivity. As shown in Proposition 3, the shock's persistence plays a crucial role in the cyclical behaviour of the net interest margin. Therefore, the model is simulated for the two alternative values of $\rho_{z}=\{0.35,0.95\}$

In both these cases, a positive technological shock leads to an expansion of the credit in the economy by two means. Firstly, an improvement in aggregate technology leads to lenders and entrepreneurs accepting a lower idiosyncratic productivity level. Because our calibration respects condition (12), the elasticity coefficient $\omega_{z}$ is negative and the IRF of $\widetilde{\omega}_{t}$ is negative in both cases. This fall in reservation productivity decreases the rate of match destruction in the economy and leads to a credit expansion.

Secondly, the improvement in aggregate technology stimulates the entry of lenders into the credit market. In Proposition 1, we showed that the elasticity $\theta_{z}>0$ and thus the IRF of $\theta_{t}$ is positive. This rise in credit market tightness facilitates the financing of entrepreneurs by increasing their matching probabilities and thus contributes to a credit expansion. However, the magnitude of the response of credit market tightness depends crucially on the shock's persistence because of the forward-looking behaviour of agents. In the case of low persistence, the increase in credit market tightness is moderate with important consequences for output and the net interest margin, as discussed below.

For output, the IRFs are positive for both values of $\rho_{z}$. However, the hump-shaped pattern, as emphasised by Den Haan et al. (2003), is no longer observed for moderately persistent shocks. For the net interest margin, the sign of its IRFs is related to the shock's persistence. When persistence is high, the net interest margin reacts negatively to the shock, leading to a negative correlation with output (approximately -0.99 ). This result is consistent with the observed countercyclical behaviour of the net interest margin in the United States, as described in Section II. If low persistence is assumed, the model loses its ability and generates a procyclical net interest margin. The small response of credit market liquidity reduces the threat point effect drastically. Therefore, entrepreneurs do not benefit from a significant improvement in liquidity and are thus unable to bargain a lower interest rate. 


\subsection{Robustness}

In order to assess the robustness of the numerical results to the specific values selected in the calibration process, Figure 6 reports the coefficient of correlation between the net interest margin and output for various structural parameters and calibrated endogenous variables. The ranges of values used are selected to satisfy the conditions of equilibrium existence and stability given in Appendix D.

When the value of a calibrated endogenous variable is changed, the overall calibration process described above is applied and we adapt the values of the structural parameters as necessary. The net interest margin becomes procyclical when $(i)$ low persistent shocks are considered (as shown in the previous subsection) and (ii) a high separation rate is imposed (for values above $40 \%$, which implies a financial relationship that lasts for less than 2.5 quarters).

\section{Relations with the Theoretical Literature}

The presented explanation of the cyclical behaviour of the net interest margin based on search frictions is not the first proposed in the literature. Business cycle models with financial frictions have been widely based on costly state verification theory, as first suggested by Townsend (1979) and later incorporated into business cycle models by Bernanke and Gertler (1989). The countercyclical behaviour of the net interest margin in this context should result from the countercyclicality of default rates. In times of economic recession, borrowers receive less compared with the value of their collateral than they do in better economic times. Further, the probability of borrowers defaulting on their loans increases in recessions and this forces banks to increase their lending rates compared with the costs of their deposits.

Carlstrom and Fuerst (1997), Gomes et al. (2003), and Covas and Den Haan (2012) all demonstrated the difficulty of this framework generating a countercyclical default rate and suggested extensions to overcome this problem. In addition, Bernanke et al. (1999) made the seminal finding that costly state verification theory is a convenient amplification 
mechanism of shock effects, but not per see a powerful propagation mechanism. The purpose of the credit market search model is thus both to generate persistent fluctuations, as demonstrated by Den Haan et al. (2003), and a countercyclical separation rate, as shown in the present paper.

The second set of explanations is linked to the macroeconomic literature on countercyclical mark-ups in markets associated with imperfect competition (e.g., Rotemberg and Woodford, 1992). One representation of this approach was proposed by Olivero (2010), who introduced a monopolistically competitive banking sector into a standard two-country, two-good business cycle model with complete asset markets. The countercyclical margin in the model presented by Olivero (2010) rested on the cyclical variations in the number of banks and in their differentiation. Corbae and D'Erasmo (2013) also focused on imperfect competition in the context of a model of banking industry dynamics based on Stackelberg monopolistic competition. This approach aimed to provide a full treatment of the bank, in particular its endogenous size. Therefore, it would be interest-

ing to adopt this approach for the credit market search model. ${ }^{18}$ Indeed, in the literature as in this paper, financial intermediation activities are linear, while bank size has no consequences on the credit market.

Recently, Aliaga-Diaz and Olivero (2012) offered another explanation of net interest margin dynamics based on deep habits. Interestingly, their explanation shares a key assumption with the credit market search model, namely the existence of switching costs. These authors introduced deep habits as a way of modelling switching costs, which are similar to the search costs considered in the present paper. Switching costs correspond to the search costs that agents must repay after separation in order to form a new match.

\section{Conclusion}

This paper formulated a credit market search model that reproduces the well known countercyclical behaviour in the net interest margins of banks. Our contribution to the body of knowledge in this regard is to demonstrate that the relevance of the credit market search model is not restricted to "quantities" (e.g., credit, output, or unemployment), 
but can also be applied to "prices" (e.g., interest rates). Credit market liquidity, measured by credit market tightness, plays a crucial role in our model because it determines the countercyclical behaviour of the net interest margin. As credit market tightness is time-varying, this model's property is in line with the research directions suggested by Petrosky-Nadeau and Wasmer (2013) . Although time-invariant in their model ${ }^{19}$, these authors clearly stated that time-varying credit market tightness is an attractive mechanism for overcoming financial issues. Finally, the presented setup explains the procyclical behaviour of liquidity on the credit market as well as the countercyclical behaviour of the net interest margin and separation rate, consistent with persistence in output fluctuations.

\section{ACKNOWLEDGEMENTS}

This paper benefited from the comments and suggestions of Hafedh Bouakez, Jerôme de Boyer des Roches, Dean Corbae, Pablo d'Erasmo, Nicolas Petrosky-Nadeau, and Etienne Wasmer as well as the seminar participants of the GDR Monnaie et Finance (Orléans, 2009), the Annual Meeting of the SED (Montréal, 2010), the Louis Bachelier Institute Seminar (Paris, 2010), the Annual Meeting of T2M (2010, Le Mans), the MSE Université Paris I Seminar (2009), and the Université de Nantes (2010). The authors also thank Samir Ifoulou for research assistance. Fabien Tripier gratefully acknowledges the financial support provided by the Chair Finance of the University of Nantes Research Foundation. Kevin Beaubrun-Diant gratefully acknowledges the financial support received from the Dauphine Research Foundation.

\footnotetext{
Notes

${ }^{1}$ The net interest margin is calculated as the difference between (i) the ratio of interest income on loans to the volume of loans and (ii) the ratio of interest income on deposits to the volume of deposits. The exact values reported in Figure 1 are $1.23 \%$ in 2001(1), 1.49\% in 2001(4), 1.16\% in 2007(4), and $1.41 \%$ in 2008(4). Figure 2 shows the cyclical components of these two series for the period 1985-2008.
} 
${ }^{2}$ Although this empirical fact is not entirely new, the full empirical analysis has only recently been provided by Aliaga-Diaz and Olivero $(2010,2011)$ and Olivero (2010). In the present paper, we closely follow the empirical approach of Aliaga-Diaz and Olivero (2010), as discussed in more detail in Section II on the empirical literature. In this section, we also describe our data and compute the correlation coefficients between the net interest margin and output for a longer time period and for various measures of the margin compared with the literature on this topic.

${ }^{3} \mathrm{~A}$ large body of knowledge on the structural determinants of the net interest margin aims to explain international differences in banking profitability as well as recent trends in this sector. For instance, Ho and Sanders (1981) and Wong (1997) developed the theoretical foundations of this topic, while DemirgüçKunt and Huizinga (1999) exemplified previous empirical works. For the macroeconomic implications of this research stream, see Tobias and Shin's (2010) work on financial intermediaries. These authors showed that the net interest margin influences monetary policy by determining the profitability of bank lending, and thus the capacity of banks to increase lending in the economy.

${ }^{4}$ Dell'Ariccia and Garibaldi (2005) and Craig and Haubrich (2013) both constructed databases of credit flows and showed that the US credit market is characterised by large cyclical flows of credit expansions and contractions that can be explained in terms of matching friction.

${ }^{5}$ The important macroeconomic consequences of credit market quantities were put forward by Den Haan et al. (2003) for output dynamics and by Wasmer and Weil (2004) and Petrosky-Nadeau and Wasmer (2013) for equilibrium unemployment. Wasmer and Weil (2004) and Besci et al. (2005) also examined equilibrium interest rates in the credit matching model, but only at the steady state and not for the business cycle as addressed in the present study.

${ }^{6}$ This basic structure of the credit matching model (i.e., an aggregate matching function and a Nash bargaining process for interest rates) was used by Wasmer and Weil (2004) and Petrosky-Nadeau and Wasmer (2013) in association with search frictions on the labour market, by Besci et al. (2005) with heterogeneous borrowers, by Petrosky-Nadeau and Wasmer (2011) in a model of search frictions on three markets (labour, credit, and goods), and by Rochon and Chamley (2011) for loan rollovers. Note that Den Haan et al. (2003) did not consider the Nash solution for the interest rate, but instead explored an agency contract with moral hazard. Liquidity shocks for lenders were also considered.

${ }^{7}$ The inclusion of the third component is necessary to generate a countercyclical net interest margin in the credit market search model. By contrast, an exogenous separation process would lead to the net interest margin being procyclical.

${ }^{8}$ The countercyclical behaviour of the default rate is a well established empirical fact (see Gomes et al. (2003) and Covas and Den Haan (2012) for the implications on the business cycle). In our model, such a separation is based on a joint decision by the lender and the borrower and cannot therefore strictly be interpreted as a default even though the two events (i.e., failure and separation) lead to the entrepreneur 
losing his or her long-term lending relationship with the bank.

${ }^{9}$ Here, we use the term "liquidity" to express the "ease and speed" experienced by an entrepreneur when his or her status switches from "unfinanced" to "financed".

${ }^{10}$ Our study period ends in 2008 in order to avoid the period of the global financial crisis. Since then, monetary policy has become unconventional, which could have modified net interest margin behaviour significantly. Although this topic is of clear research interest, it is beyond the scope the present paper.

${ }^{11}$ Corbae and D'Erasmo (2012) considered only Margin 3.

${ }^{12}$ Using the terms introduced in footnote $\mathrm{I}$, the credit market is more liquid when $\theta$ rises in the sense that entrepreneurs find "easier" and more "speedy" lenders thanks to a higher matching probability, defined as $p=\bar{m} \theta^{\chi}$.

${ }^{13}$ This equation is deduced by introducing into $R_{t}^{p}=\int_{\widetilde{\omega}_{t}}^{\bar{\omega}}\left[R_{t}^{\ell}(\omega)-R_{t}^{h}\right] d H(\omega)$ the expression of $R_{t}^{\ell}(\omega)$ given by (C.3).

${ }^{14}$ See equation (D.1), where the expected productivity for tomorrow, that is $E_{t}\left\{z_{t+1}\right\}$, determines the current credit market liquidity, $\theta_{t}$.

${ }^{15}$ See the LHS term of equation (D.2), which determines reservation productivity.

${ }^{16}$ This corresponds to $(d / \bar{m}) \theta_{t}^{1-\chi}$ in the RHS term of equation (D.2), which determines reservation productivity.

${ }^{17}$ This corresponds to $\left(-\eta \bar{m} \theta_{t}^{\chi}\right)$ in the RHS term of equation (D.2), which determines reservation productivity. See equation (C.3) for the impact of this term on the bargained loan interest rate.

${ }^{18}$ In the labour market search literature, a specific strand has demonstrated the interest of considering large firms with nonlinearities in their production or search activities (see Bertola and Caballero, 1994).

${ }^{19}$ Credit market tightness is assumed to be acyclical by Petrosky-Nadeau and Wasmer (2013) because there is a double free entry condition for entrepreneurs and banks. Petrosky-Nadeau and Wasmer (2013) considered endogenous (exogenous) participation for banks and entrepreneurs (workers), as in the seminal paper by Wasmer and Weil (2004). Because we only consider a unique frictional market, participation is endogenous on only one side of the market (here banks as well as firms in the labour market search model) and exogenous on the other (here entrepreneurs as well as workers in the labour market search model). 


\section{REFERENCES}

ADRIAN, T., SHIN, H.S., 2010. Financial Intermediaries and Monetary Economics, Chapter 12 in Handbook of Monetary Economics, Volume 3, edited by B. M. Friedman and M. Woodford, 601-650.

ALIAGA-DIAZ, Roger A. and OLIVERO, Maria P. "The Cyclicality of Price-Cost Margins in Credit Markets: Evidence from US Banks" ECONOMIC INQUIRY 49.1 (Jan 2011):26-46

ALIAGA-DIAZ, Roger A. and OLIVERO, Maria P. "Is there a Financial Accelerator in US Banking? Evidence from the Cyclicality of Banks' Price-Cost Margins" ECONOMICS LETTERS 108.2 (Aug 2010):167-171

BECSI, Z., LI., V.E. and WANG, P. (2005). Heterogeneous borrowers, liquidity, and the search for credit. Journal of Economic Dynamics and Control. 29 (8), 1331-1360.

BERNANKE, B. S. and GERTLER, M. (1989). Agency costs, net worth, and business fluctuations. American Economic Review, 79 (1), 14-31.

BERTOLA, G., and CABALLERO, R. J. (1994). Cross-sectional efficiency and labour hoarding in a matching model of unemployment. The Review of Economic Studies, 61(3), $435-456$.

CHAMLEY, C. and ROCHON, C. (2011). From search to match: when loan contracts are too long. Journal of Money, Credit and Banking, 43, 385-411.

CORBAE, D. and D'Erasmo, P. (2011). A quantitative model of banking industry dynamics. Working paper.

COVAS, F. and DENHAAN, W.J., (2012). The Role of Debt and Equity Finance Over the Business Cycle. The Economic Journal vol. 122, Iss. 565, 1262-1286.

CRAIG, B.R. and HAUBRICH, J.G. (2013). Gross loan flows. Journal of Money, Credit and Banking 45 (2-3), 401-421.

DELL'ARICCIA, G. and GARIBALDI, P. (2005). Gross credit flows. Review of Economic Studies 72 (3), 665-685.

DEMIRGUC-KUNT, A., and H. HUIZINGA (1999). Determinants of Commercial Bank Interest Margins and Profitability: Some International Evidence, World Bank Economic 
Review 13(2), 279-408.

DEN HAAN, W.J., RAMEY, G. and WATSON, J. (2003). Liquidity flows and fragility of business enterprises. Journal of Monetary Economics 50 (6), 1215-1241.

DIAMOND, P. A. (1982), Wage determination and efficiency in search equilibrium. Review of Economic Studies, 49, 217-27.

GOMES, J., A. YARON and L. ZHANG, 2003, Asset Pricing and Business Cycles with Costly External Finance", Review of Economic Dynamics, vol. 6, 767-788.

HO, T., and A. SAUNDERS, 1981. The determinants of bank interest margins: theory and empirical evidence. Journal of Financial and Quantitative Analyses 16, 581-600.

IACOVIELLO, M. (2011). Financial business cycles. Federal Reserve Board.

KOLLMANN, R. (2012). Global banks, financial shocks and international business cycles: Evidence from estimated models. Working Papers ECARES ECARES.

MORTENSEN, D.T. and PISSARIDES, C.A. (1994). Job creation and job destruction in the theory of unemployment. Review of Economic Studies, 61 (3), 397-415.

OLIVERO, M.P. (2010). Market power in banking, countercyclical margins and the international transmission of business cycles. Journal of International Economics. 80 (2). 292-301.

PETROSKY-NADEAU, N. and WASMER, E. (2011). Macroeconomic dynamics in a model of goods, labor and credit market frictions. IZA Discussion Papers 5763.

PETROSKY-NADEAU, N. and WASMER, E. (2013). The Cyclical Volatility of Labor Markets under Frictional Financial Markets American Economic Journal: Macroeconomics 5(1), 1-31.

PISSARIDES, C.A. (2000). Equilibrium unemployment theory. MIT Press.

ROTEMBERG, J.J. and WOODFORD, M. (1992). Oligopolistic pricing and the effects of aggregate demand on economic activity. Journal of Political Economy, 100 (6), 1153-1207. RAJAN, R.G. (1992). Insiders and outsiders: The choice between informed and arm's length debt. Journal of Finance 47, 1367-1400.

SANTOS, J.A.C and WINTON, A. (2008). Bank loans, bonds, and information monopolies across the business cycle. Journal of Finance, LXIII (3), 1315-59 
TOBIAS, A.and SHIN, H.S. (2010). "Liquidity and leverage," Journal of Financial Intermediation, Elsevier, vol. 19(3), 418-437.

TOBIAS, A.and SHIN, H.S. (2010). "The Changing Nature of Financial Intermediation and the Financial Crisis of 2007-2009," Annual Review of Economics, Annual Reviews, vol. 2(1), 603-618.

TOWNSEND, R. (1979). Optimal contracts and competitive markets with costly state verification. Journal of Economic Theory, 21, 265-93.

WASMER, E. and WEIL, P. (2004). The Macroeconomics of labor and credit market imperfections. American Economic Review 94 (4), 944-963.

WONG, K.P. (1997). On the determinants of bank interest margins under credit and interest rate risks. Journal of Banking and Finance 21, 251-271. 


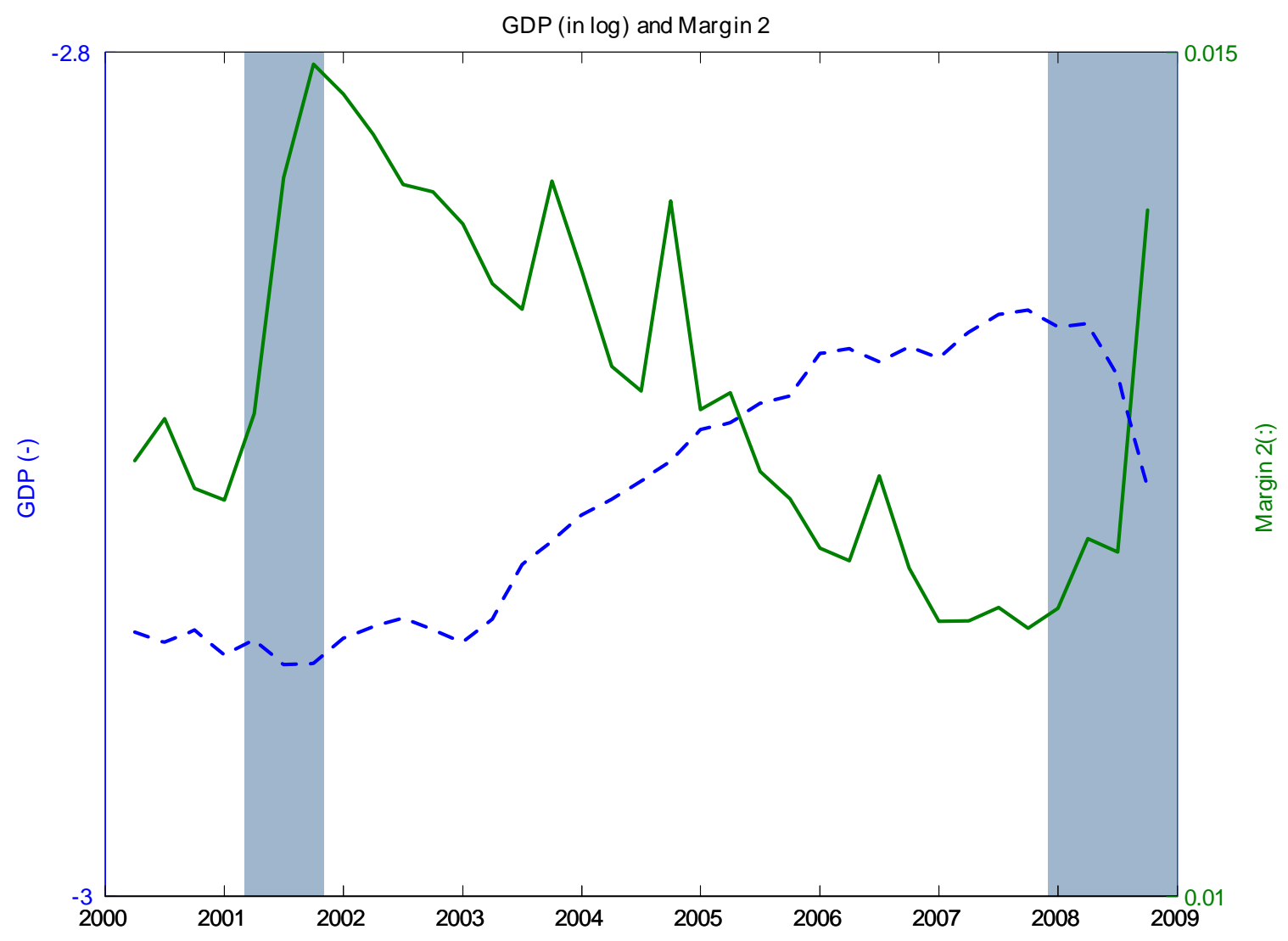

Figure 1: Output and net interest margin during the two last recessions and the expansion phase of 2002-2007.

\section{Tables and Figures}




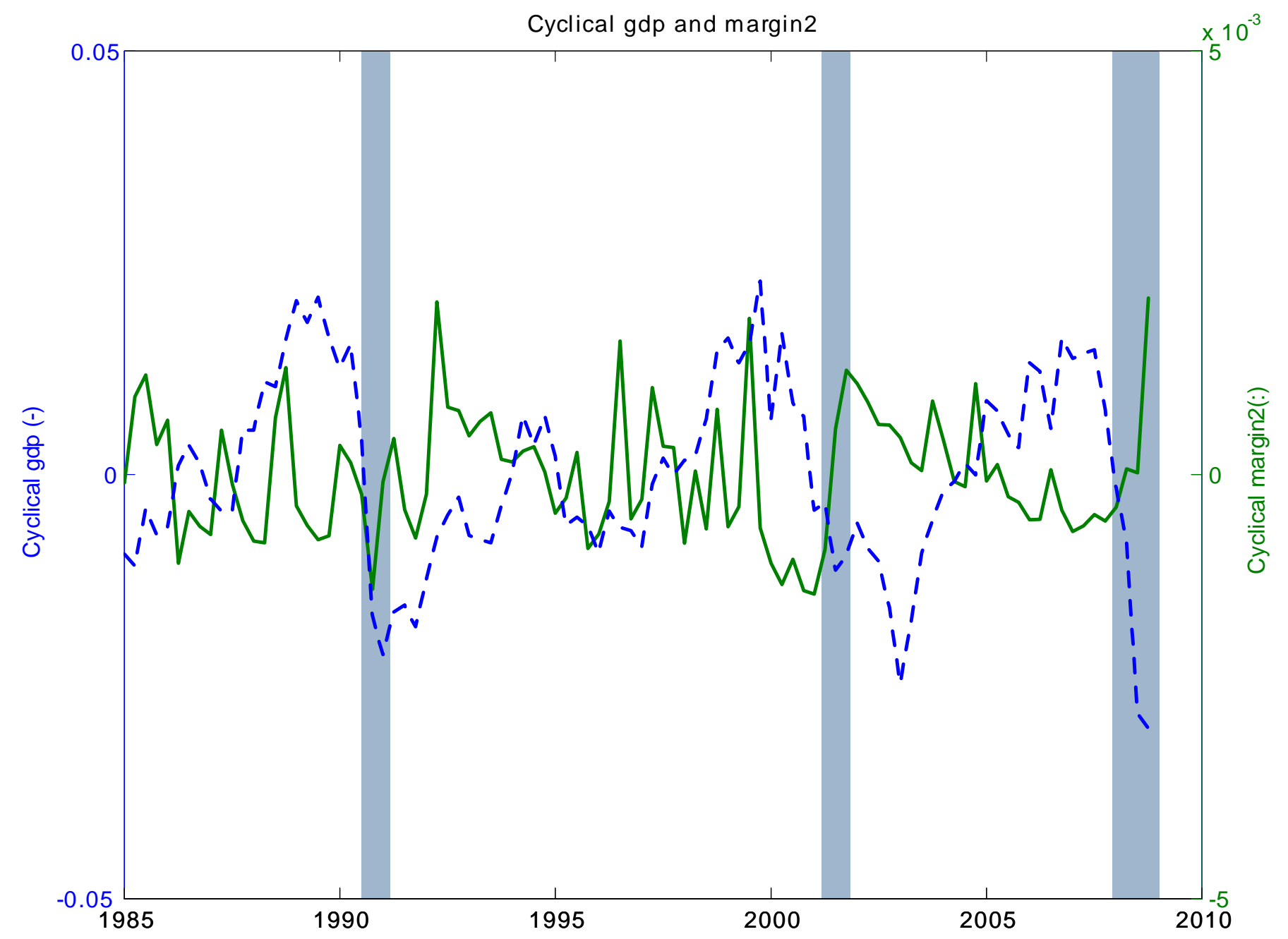

Figure 2: Cyclical components of GDP (in log) and of the net interest margin (HP Filter 1600).

Table 1. Sample Relative Volatility and Correlations with GDP

(level of significance in parenthesis)

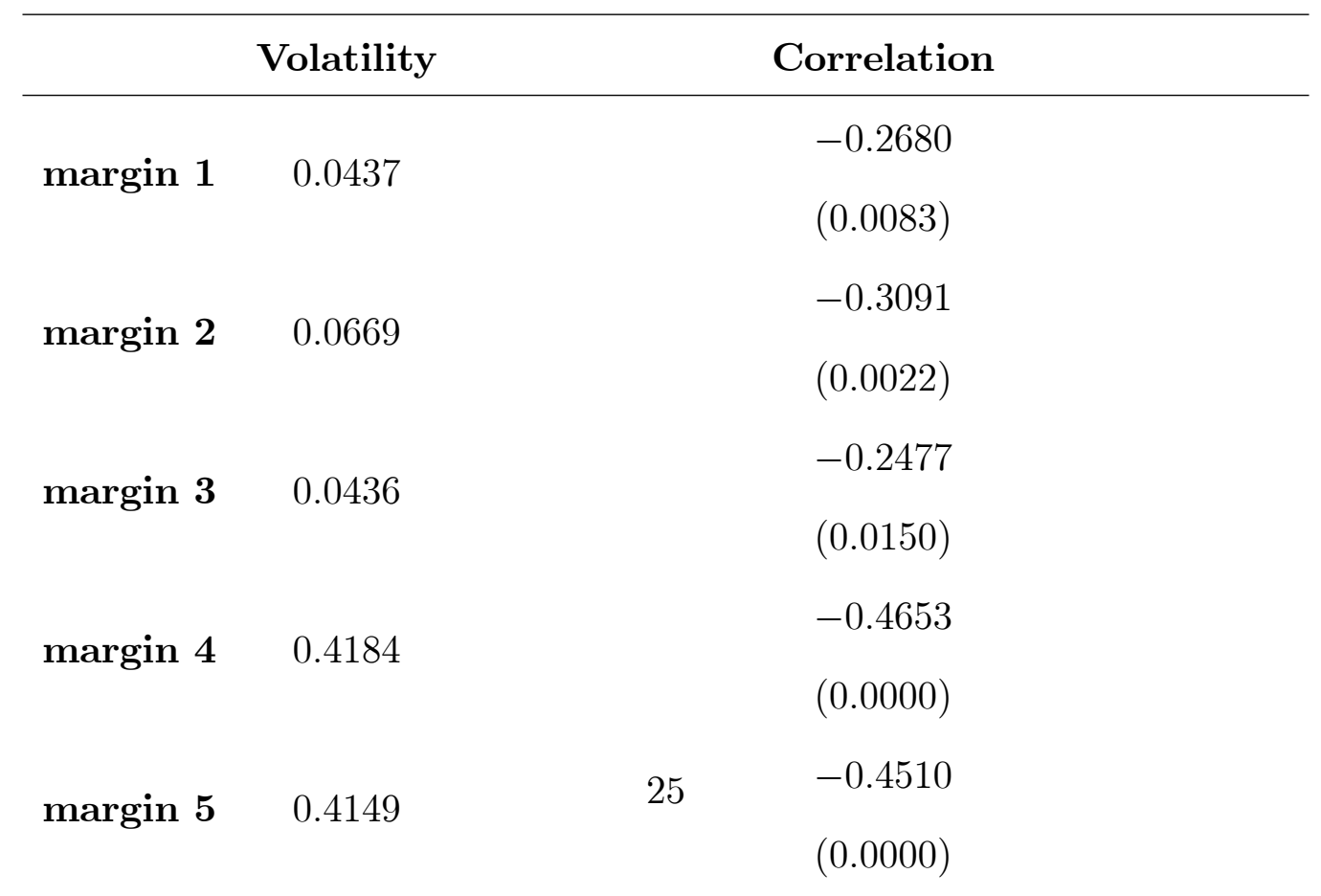



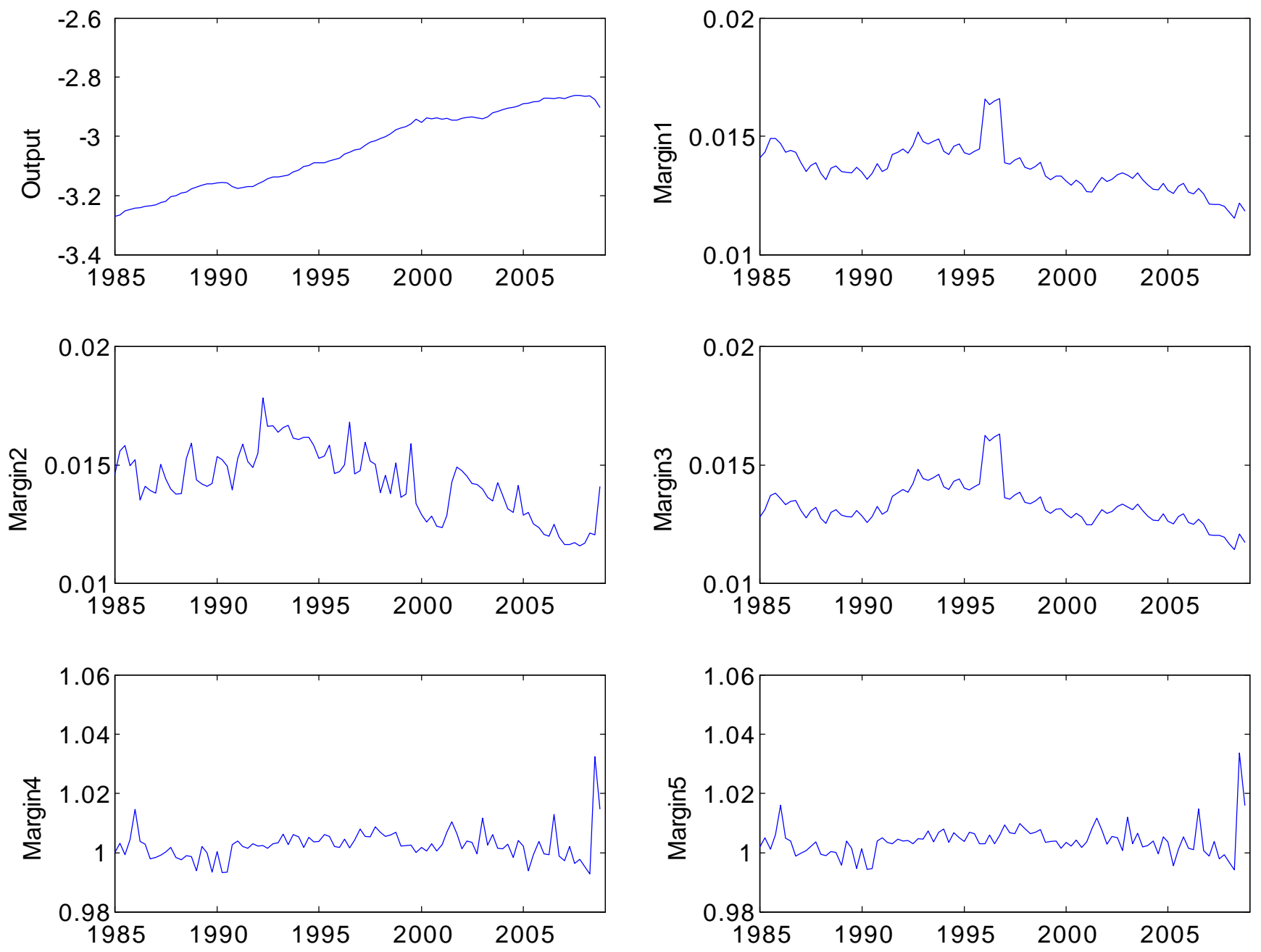

Figure 3: Historical times series of margins and gdp as a measure of the cycle 

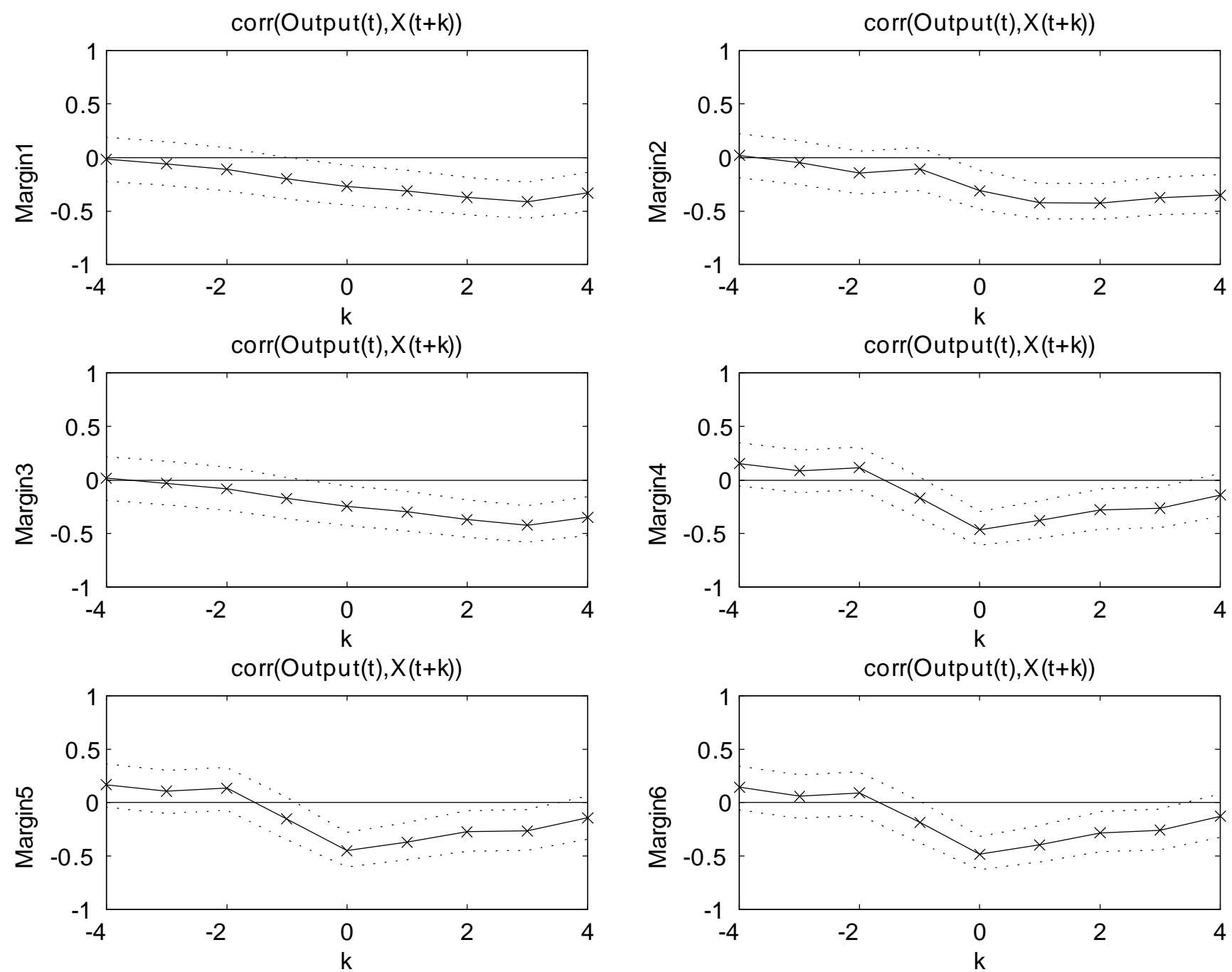

Figure 4: Dynamic correlations of all margins with output 
1a. Output

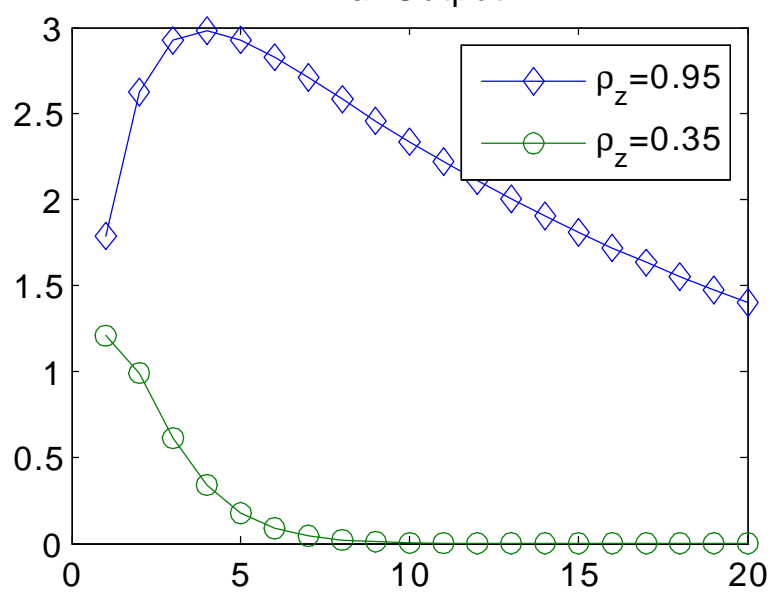

1c. Separation Rate

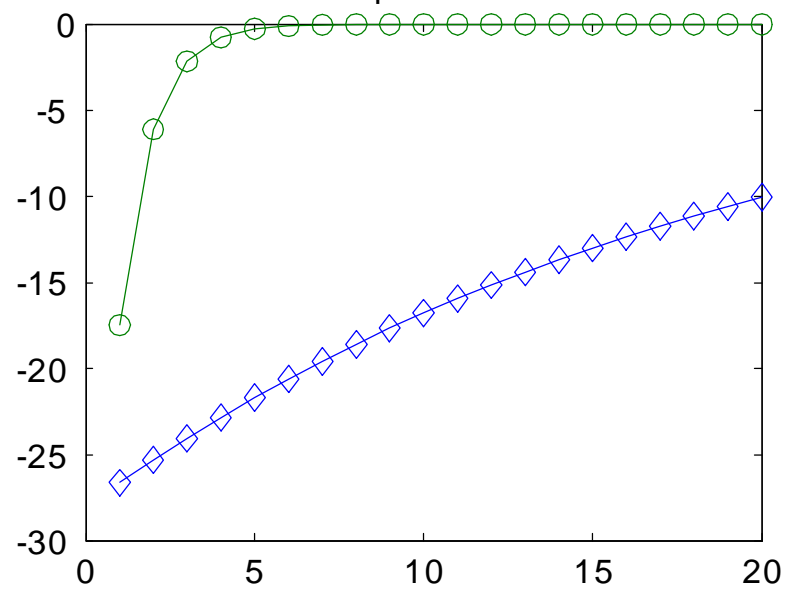

1b. Interest Rate Margin

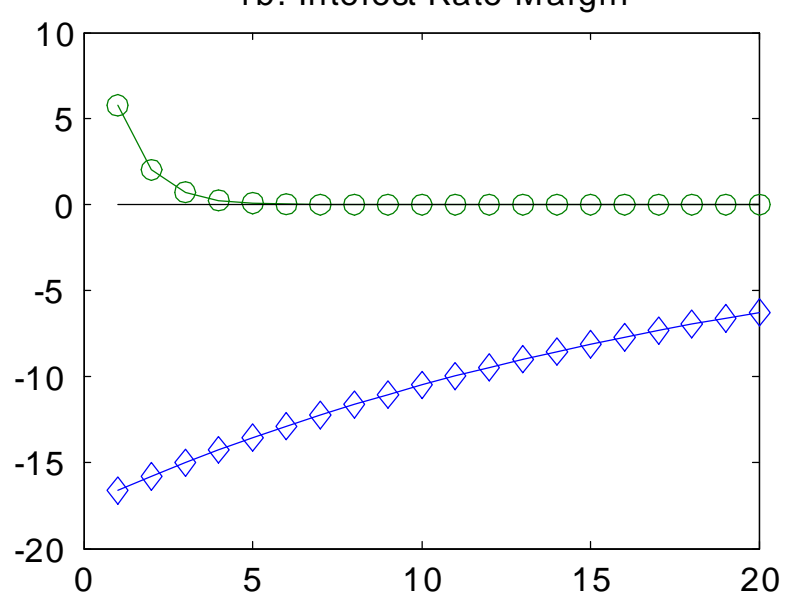

1d. Credit Market Tightness

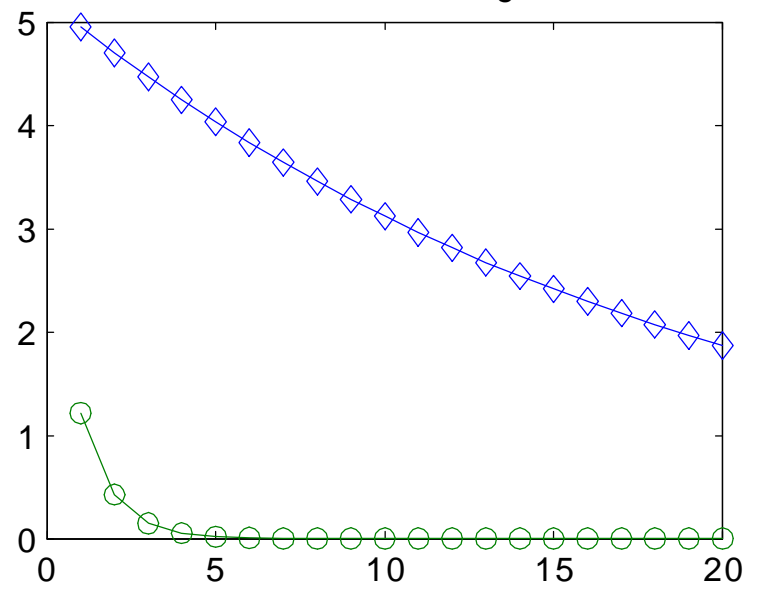

Figure 5: IRFs of endogenous variables to the technological shock with a persistence of shocks equal to $\rho=0.95$ (the lines with diamonds) and equal to $\rho=0.35$ (the lines with circles). 

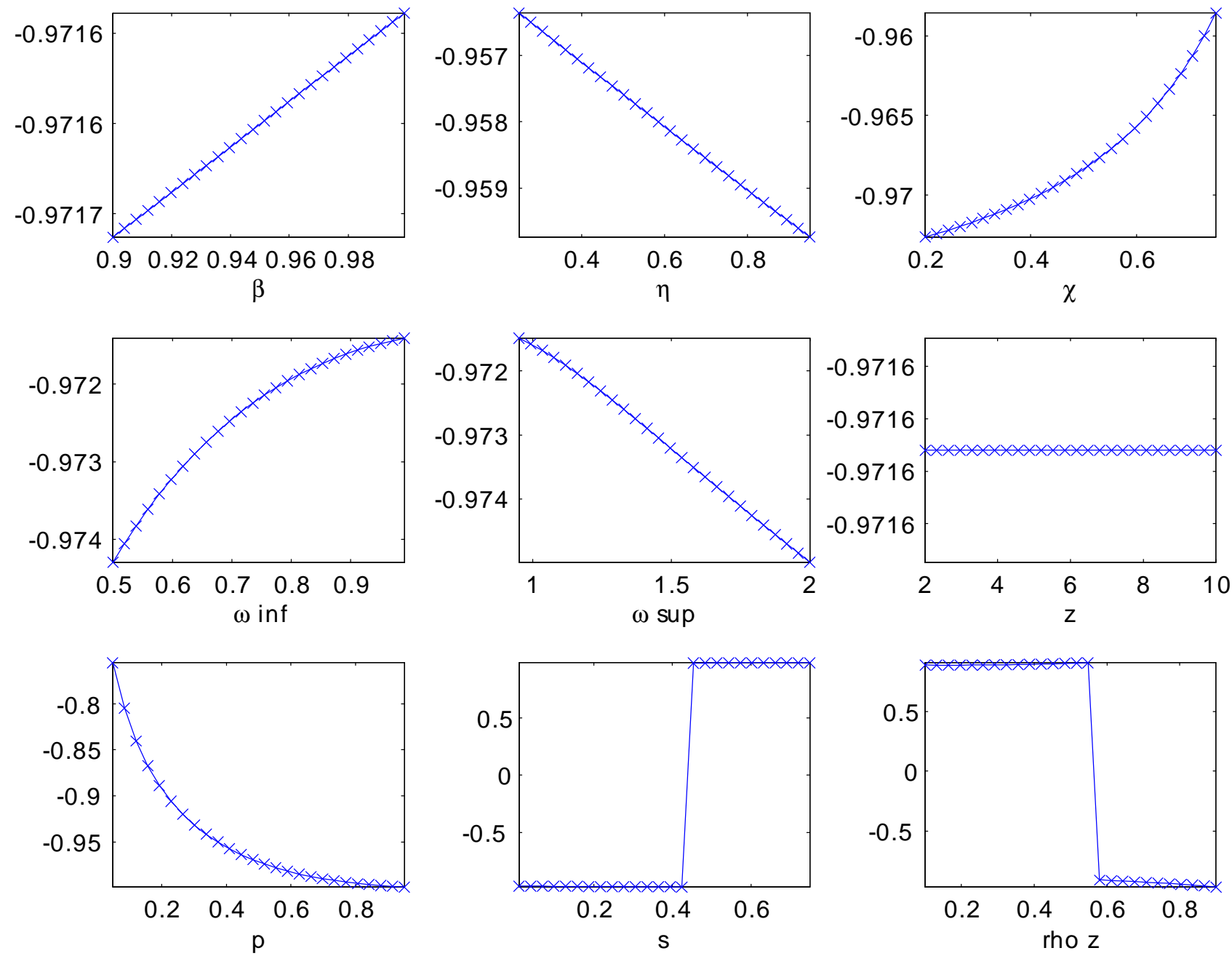

Figure 6: Coefficient of correlation between the net interest margin and output for various values of structural parameters and of calibrated endogenous variables. 


\section{Appendix}

\section{A Data Appendix}

We focus on individual commercial banks in the U.S. The dataset compiled data from 1985 to 2008. Time series were constructed taking into account "Notes on forming consistent time series" provided by the Call Reports on Condition and Income data (available in the Federal Reserve Bank of Chicago website). We also follow Kashyap and Stein (1997), Corbae and D'Erasmo (2013) and Aliaga-Diaz and Olivero (2011).

Firstly, data was cleaned to avoid the result to be affected by outlier and other obvious data problems: data for which total assets or total loans are zero or missing were deleted. Then, banks in US territories were dropped from the database.

Secondly, banks interest income, expenses are all measured as cumulative year to date totals. So we apply the appropriate adjustment to get the corresponding values for each quarter. As a result, banks for which there is no date in at least one of the four quarter, in a given year, were not included in the computation of the net of the net interest margin of that year.

Finally, we keep some definitions that are based on individual bank level (See Table A.1), from Aliaga-Diaz and Olivero (2011) and from Corbae and D'Erasmo (2013). When computing individual net interest margins we restrict our sample to the interval of \pm five standard definition from the mean to control the effect of outliers. We also put in the analysis of the net interest margin two time series available on the FRED database. To deflate balance sheets and income statements variables we use the CPI index. Variables are detrended using the HP filter. 
Table A.1. Variables Definitions

\section{Variable Description}

margin 1 Int. income on loans/loans net of loans past 90 days due-int. expense on deposit/total deposits ; (riad4010/(rcfd2122-rcfd1407)-riad4170/rcfd2200).

margin 2 (Total int. income-int. expenses)/Total loans; (riad4107-riad4073)/rcfd1400.

margin 3 (Int. income from loans/Loans) - (Expense from Deposits/Deposits); $\operatorname{riad} 4010 /(\operatorname{rcfd} 1400-\operatorname{rcfd} 2165)-\operatorname{riad} 4170 / \operatorname{rcfd} 2200$.

margin 4 NIMUS - The Net Interest Margin for all US banks - FRED Database.

margin 5 NIM1US - The net interest margin for all US banks with average assets under 1 billion of dollars from FRED Database.

margin 6 Bank Prime loan - Treasury Bill rate (3 months secondary market).

GDPpc Real Gross Domestic Product, 1 Decimal (GDPC1) in billions of chained 2005 US doll and Civilian Noninstitutional Population (CNP16OV) U.S. Department of Labor: Bureau of Labor Statistics.

CPI Consumer Price Index - Consumer Price Index for All Urban Consumers. All Items (CPIAUCSL) Index 1982-84=100. 


\section{B Value Functions}

\section{Entrepreneurs}

The value functions $J_{t}^{a}(\omega)$ and $V_{t}^{e}$ are defined as follows

(B.1) $J_{t}^{a}(\omega)=z_{t} \omega-x^{e}-R_{t}^{\ell}(\omega)+\beta \mathrm{E}_{t}\left\{\int_{\underline{\omega}}^{\bar{\omega}} J_{t+1}(\omega) d G_{t+1}(\omega)\right\}$

$$
V_{t}^{e}=p_{t} \beta \mathrm{E}_{t}\left\{\int_{\underline{\omega}}^{\bar{\omega}} J_{t+1}(\omega) d G_{t+1}(\omega)\right\}+\left(1-p_{t}\right) \beta \mathrm{E}_{t}\left\{V_{t+1}^{e}\right\}
$$

where $\beta$ is the discount rate, $z_{t} \omega$ represent the value of production, $R_{t}^{\ell}(\omega)$ is the credit interests, and $x^{e}$ represents the fixed costs of production. We introduce fixed costs of production to ensure the existence of a positive value for the productivity reservation $\widetilde{\omega}$. The probability that an entrepreneur does not find a lender is given by $\left(1-p_{t}\right)$, in which case he must turn to the credit market in the next period. It should be noticed that being matched with a lender does not necessarily ensure that the entrepreneur is awarded funds for his project. The decision to finance the project depends on the realized value of $\omega$.

In order to solve the bargaining process, we compute the net surplus of being matched from an entrepreneur's perspective

$$
\begin{aligned}
(\mathrm{B} .3) J_{t}^{a}(\omega)-V_{t}^{e}= & z_{t} \omega-x^{e}-R_{t}^{\ell}(\omega) \\
& +\left(1-p_{t}\right) \beta \mathrm{E}_{t}\left\{\int_{\underline{\omega}}^{\bar{\omega}}\left[J_{t+1}(\omega)-V_{t+1}^{e}\right] d G_{t+1}(\omega)\right\}
\end{aligned}
$$

Equation (B.3) states that an entrepreneur's net surplus is the sum of the revenue per period (total sales less production and credit costs) plus the expected value of the net surplus in the next period. The entrepreneur gets the net surplus at the new period with a probability of 1 if matched and $p_{t}$ if unmatched. Here, the term $\left(1-p_{t}\right)$ represents the difference between the matching probabilities of the two states. 


\section{Banks}

The value functions $\Pi_{t}^{a}(\omega)$ and $V_{t}^{b}$ are defined as follows

$$
\Pi_{t}^{a}(\omega)=R_{t}^{\ell}(\omega)-R^{h}-x^{b}+\beta \mathrm{E}_{t}\left\{\int_{\underline{\omega}}^{\bar{\omega}} \Pi_{t+1}(\omega) d G(\omega)\right\}
$$

$$
V_{t}^{b}=-d+q_{t} \beta \mathrm{E}_{t}\left\{\int_{\underline{\omega}}^{\bar{\omega}} \Pi_{t+1}(\omega) d G(\omega)\right\}+\left(1-q_{t}\right) \beta \mathrm{E}_{t}\left\{V_{t+1}^{b}\right\}
$$

where $\beta$ is the same discount rate as for entrepreneurs, $R_{t}^{\ell}(\omega)$ denotes the revenue generated by the credit activity, $R^{h}$ represents the cost of the resources, $x^{b}$ is the fixed cost of managing the project, $d$ represents the per-period cost of search, and $q_{t}$ is the matching probability for a financial intermediary. When matched to an entrepreneur, the net surplus of a financial intermediary is

$$
\begin{aligned}
\Pi_{t}^{a}(\omega)-V_{t}^{b}= & R_{t}^{\ell}(\omega)-R^{h}-x^{b}+d \\
& +\left(1-q_{t}\right) \beta \mathrm{E}_{t}\left\{\int_{\underline{\omega}}^{\bar{\omega}}\left\{\Pi_{t+1}(\omega)-V_{t+1}^{b}\right\} d G(\omega)\right\}
\end{aligned}
$$

A lender's net surplus (Equation (B.6)) is the sum of the per period income (the credit interests, minus the cost of resources, the cost of the project management, plus the search cost unpaid when matched) plus the expected value of the net surplus in the next period. The lender gets the net surplus at the new period with a probability of 1 if matched and $q_{t}$ if unmatched. Here, the term $\left(1-q_{t}\right)$ represents the difference between the matching probabilities of the two states.

\section{Equilibrium Decisions for the Loan Interest Rate, Separation, and Entry}

We assume that the costs of search in the credit market are completely borne by the lenders and that all unmatched entrepreneurs search for funds on the credit market. The endogenous entry of lenders determines the tightness of the credit market. The free entry 
condition on the credit market implies that $V_{t}^{b}=0$. From (B.5), we deduce that

(C.1) $\frac{d}{q_{t}}=\beta \mathrm{E}_{t}\left\{\int_{\underline{\omega}}^{\bar{\omega}} \Pi_{t+1}(\omega) d G(\omega)\right\}=\beta \mathrm{E}_{t}\left\{\int_{\widetilde{\omega}_{t+1}}^{\bar{\omega}} \Pi_{t+1}^{a}(\omega) d G(\omega)\right\}$

since $\mathrm{E}_{t}\left\{V_{t+1}^{b}\right\}=0$. The lenders' surplus (B.6) then becomes under the free entry condition

(C.2) $\Pi_{t}^{a}(\omega)-V_{t}^{b}=R_{t}^{\ell}(\omega)-R_{t}^{h}-x^{b}+\frac{d}{q_{t}}$.

In equation (C.2), the new variable, $d / q_{t}$, represents the current average cost of a match. From (C.1), this equals the expected value of a match for the next period. The equilibrium credit interest rate is deduced from (6), (B.3), (C.1) and (C.2)

(C.3) $R_{t}^{\ell}(\omega)=(1-\eta)\left(z_{t} \omega-x^{e}\right)+\eta\left(x^{b}+R^{h}-p_{t} \frac{d}{q_{t}}\right)$

where $R_{t}^{\ell}(\omega)$ represents the lender's revenues. The equilibrium value of these revenues is an average of two terms weighted according to the bargaining powers represented by $(1-\eta)$ and $\eta$. The first term is the net production profit, defined as the amount of total output, $z_{t} \omega$, minus the total cost, $x^{e}$. The second term represents the fixed cost for the lender, $x^{b}$, plus the cost of the resources, $R_{t}^{h}$, minus the entrepreneur's outside opportunity, $p_{t} \times d / q_{t}$. An increase in the credit market tightness (namely $\theta_{t}=p_{t} / q_{t}$ ) improves the outside opportunity of entrepreneurs, thus diminishing the lender's payoff.

The separation rule is deduced from equations (7) and (C.2)

(C.4) $R_{t}^{\ell}\left(\widetilde{\omega}_{t}\right)+\frac{d}{q_{t}}=R^{h}+x^{b}$

The term on the LHS is the value of a match for a lender, defined as the sum of the credit activity revenues, $R_{t}^{\ell}\left(\widetilde{\omega}_{t}\right)$, and the expected value of a match at the next period, $d / q_{t}$. A lender would maintain a match if, and only if, its value is at least higher than the cost of the match (the term on the RHS), equal to the cost of the resources lent, $R^{h}$, plus the cost of managing the project, $x^{b}$. 
Given the equilibrium interest rate from (C.3), the separation rule (C.4) may then be written as

(C.5) $z_{t} \widetilde{\omega}_{t}-x^{e}+\left(\frac{1-\eta p_{t}}{1-\eta}\right) \frac{d}{q_{t}}=R_{t}^{h}+x^{b}$

and the free entry condition (C.1) written as

(C.6) $\frac{d}{q_{t}}=\beta \mathrm{E}_{t}\left\{\int_{\widetilde{\omega}_{t+1}}^{\bar{\omega}}\left[R_{t+1}^{\ell}(\omega)-R_{t+1}^{h}-x_{t+1}^{b}+\frac{d}{q_{t+1}}\right] d G(\omega)\right\}$

The free entry condition implies that lenders enter the credit market (bearing a cost $d$ with a probability $q_{t}$ to find a partner) until the current expected cost of matching equals the present value of the anticipated lender's surplus for the match concerned.

We restrict our attention to three aggregate variables, namely $R_{t}^{p}$, the average net interest margin, $Y_{t}$, the total output, and, $L_{t}$, the total credit in the economy. This last variable is equal to the number of financed entrepreneurs, $N_{t}$, because the value of each individual loan is normalised to the unity: $L_{t}=N_{t}=n_{t} E$. The total output is the product of the number of financed entrepreneurs, $N_{t}$, the aggregate productivity level, $z_{t}$, and the average productivity of the entrepreneurs

(C.7) $Y_{t}=N_{t} z_{t}\left(\frac{\bar{\omega}+\widetilde{\omega}_{t}}{2}\right)$

The expression is derived from $Y_{t}=n_{t} z_{t} \int_{\widetilde{\omega}_{t}}^{\bar{\omega}_{t}} \omega d H(\omega)$ where $H(\omega)$ is the distribution function of $\omega$ for the matched entrepreneurs (who have $\omega$ above $\widetilde{\omega}_{t}$, the productivity of reservation). This function satisfies $d H(\omega) / d(\omega)=1 /\left(\bar{\omega}-\widetilde{\omega}_{t}\right)$.

\section{Definition, Existence, and Stability of the equilibrium}

We firstly define equilibrium, and then yield the conditions for its existence, its uniqueness, and its stability. In order to establish the existence and uniqueness of the equilibrium, 
we reduce the equilibrium to a four-dimensional system for the variables $\left\{\theta_{t}, \widetilde{\omega}_{t}, R_{t}^{p}, z_{t}\right\}$. To this end, we reformulate the free entry condition and separation rule according to the following definition.

Definition 1 The reduced model is a set of endogenous variables $\left\{\theta_{t}, \widetilde{\omega}_{t}, R_{t}^{p}, z_{t}\right\}$ that satisfies four equations, given the set of structural parameters. The first equation is the free entry condition (C.6) that becomes

(D.1) $\frac{d}{\bar{m}} \theta_{t}^{1-\chi}=\frac{(1-\eta)}{2(\bar{\omega}-\underline{\omega})} \beta \mathrm{E}_{t}\left\{z_{t+1}\left(\bar{\omega}-\widetilde{\omega}_{t+1}\right)^{2}\right\}$

using the interest rate definition (C.3), the matching probability (1), and the separation rule (C.5). The equilibrium value of the credit market tightness $\theta_{t}$ depends on the expected values for the technological shock, $\mathrm{E}_{t}\left\{z_{t+1}\right\}$, and for the productivity reservation, $\mathrm{E}_{t}\left\{\widetilde{\omega}_{t+1}\right\}$. The second equation is the separation rule (C.5) that becomes

(D.2) $z_{t} \widetilde{\omega}_{t}=x^{b}+x^{e}+R^{h}-\left(\frac{1-\eta \bar{m} \theta_{t}^{\chi}}{1-\eta}\right) \frac{d}{\bar{m}} \theta_{t}^{1-\chi}$

using the equations for the rates of matching given in (1) and (2). The equilibrium value for the productivity reservation $\widetilde{\omega}_{t}$ depends on the current values of the technological shock, $z_{t}$, and the credit market tightness, $\theta_{t}$. The third equation is (9), which gives the equilibrium value of the credit spread as a function of the credit market tightness, $\theta_{t}$, the reservation productivity, $\omega_{t}$, and the technological shock, $z_{t}$. The fourth and last equation is the law of motion of the aggregate technology $z_{t}$

(D.3) $\log \left(z_{t+1}\right)=\rho_{z} \log \left(z_{t}\right)+\left(1-\rho_{z}\right) \log (z)+\varepsilon_{z, t+1}$

where $z$ is the steady-state value of $z_{t}, \rho_{z}$ is the persistence parameter, and $\varepsilon_{z} \sim$ iid $\left(0, \sigma_{z}^{2}\right)$ is the innovation, which variance is $\sigma_{z}^{2}$.

The following proposition establishes the existence and uniqueness conditions of the reduced equilibrium. 
Proposition 4 The steady-state equilibrium $\left\{\theta^{*}, \widetilde{\omega}^{*}, R^{p}, z\right\}$ of the model defined in Definition 1 exists and is unique, if the following condition is satisfied

$$
\text { (D.4) } \begin{aligned}
\frac{x^{b}+x^{e}+R^{h}}{z}< & \bar{\omega}<\frac{x^{b}+x^{e}+R^{h}}{z}-\frac{\beta \Delta}{2} \\
& +\eta \bar{m}\left(\frac{(1-\eta) z \bar{m}}{d}\right)^{\chi /(1-\chi)}\left(\frac{\beta \Delta}{2}\right)^{\chi /(1-\chi)}
\end{aligned}
$$

in which an additional parameter has been introduced: $\Delta=\bar{\omega}-\underline{\omega}$. This condition is necessary and sufficient.

Proof. In order to prove Proposition 4, we first define the function $\theta^{*}\left(\widetilde{\omega} ; \boldsymbol{\xi}_{\theta}\right)$ that gives $\theta^{*}$ as a function of $\widetilde{\omega}$ and a set of structural parameters $\boldsymbol{\xi}_{\theta}=\{\beta, \eta, z, \bar{m}, \bar{\omega}, \underline{\omega}\}$

$(\mathrm{D} .5) \theta^{*}\left(\widetilde{\omega} ; \boldsymbol{\xi}_{\theta}\right)=\left[\frac{\beta(1-\eta) z \bar{m}}{2(\bar{\omega}-\underline{\omega}) d}(\bar{\omega}-\widetilde{\omega})^{2}\right]^{1 /(1-\chi)}$

This function is obtained from the steady-state expression of (D.1). The limit values for $\theta^{*}$ are

$$
\begin{aligned}
\lim _{\widetilde{\omega} \rightarrow \underline{\omega}} \theta^{*}\left(\widetilde{\omega} ; \boldsymbol{\xi}_{\theta}\right) & =\left.\theta^{*}\left(\widetilde{\omega} ; \boldsymbol{\xi}_{\theta}\right)\right|_{\widetilde{\omega} \rightarrow \underline{\omega}}=\left[\frac{\beta(1-\eta) z \bar{m}}{2(\bar{\omega}-\underline{\omega}) d} \Delta^{2}\right]^{1 /(1-\chi)}>0 \\
\lim _{\widetilde{\omega} \rightarrow \bar{\omega}} \theta^{*}\left(\widetilde{\omega} ; \boldsymbol{\xi}_{\theta}\right) & =0
\end{aligned}
$$

If $\left.\widetilde{\omega}^{*} \in\right] \underline{\omega}, \bar{\omega}\left[\right.$ exists and is unique, the Equation (D.5) implies that $\theta^{*}$ exists, is unique, and satisfies $\left.\theta^{*} \in\right] 0,\left.\theta^{*}\left(\widetilde{\omega} ; \boldsymbol{\xi}_{\theta}\right)\right|_{\widetilde{\omega} \rightarrow \underline{\omega}}[$. In order to establish the existence and uniqueness of $\widetilde{\omega}^{*}$, we introduce the steady-state expression of Equation (D.2) into Equation (D.5) and deduce that $\left.\widetilde{\omega}^{*} \in\right] \underline{\omega}, \bar{\omega}[$ is the solution of

(D.6) $T\left(\widetilde{\omega}^{*} ; \boldsymbol{\xi}_{\omega}\right)=0$

where $\boldsymbol{\xi}_{\omega}=\left(x^{b}, x^{e}, a, R^{h}, z, \eta, \bar{m}, d, \beta, \bar{\omega}, \underline{\omega}\right)$ is a set of structural parameters and the func- 
tion $T\left(\widetilde{\omega}^{*} ; \boldsymbol{\xi}_{\omega}\right)$ is

$$
\begin{aligned}
(\mathrm{D} .7) T\left(\widetilde{\omega} ; \boldsymbol{\xi}_{\omega}\right)= & \frac{x^{b}+x^{e}+R^{h}}{z}-\frac{\beta(\bar{\omega}-\widetilde{\omega})^{2}}{2(\bar{\omega}-\underline{\omega})}-\widetilde{\omega} \\
& +\eta \bar{m}\left(\frac{(1-\eta) z \bar{m}}{d}\right)^{\chi /(1-\chi)}\left(\frac{\beta}{2 \Delta}\right)^{\chi /(1-\chi)}(\bar{\omega}-\widetilde{\omega})^{2 /(1-\chi)}
\end{aligned}
$$

In order to find the solution for Equation (D.6), we first note that $T\left(\widetilde{\omega} ; \boldsymbol{\xi}_{\omega}\right)$ is strictly decreasing with respect to $\widetilde{\omega}$. Hence, the existence and uniqueness of the equilibrium value $\widetilde{\omega}^{*}$ requires that $\lim _{\widetilde{\omega} \rightarrow \omega} T(\widetilde{\omega} ; \boldsymbol{\zeta})>0$ and $\lim _{\widetilde{\omega} \rightarrow \bar{\omega}} T(\widetilde{\omega} ; \boldsymbol{\zeta})<0$. The deduction of $(D .4)$ is then straightforward given the two expressions of the limits of the function $T(\widetilde{\omega} ; \boldsymbol{\zeta})$.

To discuss the theoretical properties of the credit market cycle, we log-linearized the system around its unique steady-state.

Definition 2 The log-linearized version of the reduced model is

$$
(1-\chi) \widehat{\theta}_{t}=\mathrm{E}_{t}\left\{\widehat{z}_{t+1}-2 \frac{\widetilde{\omega}}{\bar{\omega}-\widetilde{\omega}} \widehat{\widetilde{\omega}}_{t+1}\right\}
$$

(D.9) $z \widetilde{\omega} \widehat{\widetilde{\omega}}_{t}=-\left(\frac{1}{\bar{m}} \theta^{-\chi}-\frac{\eta}{1-\chi}\right)\left(\frac{1-\chi}{1-\eta}\right) d \theta \widehat{\theta}_{t}-z \widetilde{\omega} \widehat{z}_{t}$

(D.10) $R^{p} \widehat{R}_{t}^{p}=(1-\eta)\left(\frac{\bar{\omega}+\widetilde{\omega}}{2}\right) z \widehat{z}_{t}+(1-\eta) \frac{z}{2} \widehat{\widetilde{\omega}}_{t}-\eta \widehat{d \theta}_{t}$

(D.11) $\widehat{z}_{t}=\rho_{z} \widehat{z}_{t-1}+\varepsilon_{t}$

where the log-deviation of the variable $x$ is denoted $\widehat{x}_{t}=\log \left(x_{t} / x\right)$ for $x=\theta, \widetilde{\omega}, R^{p}$, and $z$. We denote $x_{z}$ as the elasticity of the endogenous variable $x_{t}$ to the shock $z_{t}$ that satisfies $\widehat{x}_{t}=x_{z} \times \widehat{z}_{t}$ for $x=\theta, \widetilde{\omega}$, and $R^{p}$. The elasticities of $\left\{\theta_{t}, \widetilde{\omega}_{t}, R_{t}^{p}\right\}$ are

$$
\theta_{z}=\left(\frac{\rho_{z}}{1-\chi}\right)\left(\frac{\bar{\omega}+\widetilde{\omega}}{\bar{\omega}-\widetilde{\omega}}\right)\left[1-\frac{2 \theta d}{z(\bar{\omega}-\widetilde{\omega})}\left(\frac{1}{\bar{m} \theta^{\chi}}-\frac{\eta}{1-\chi}\right) \rho_{z}\right]^{-1}
$$

(D.13) $\widetilde{\omega}_{z}=-\left(\frac{1}{\bar{m} \theta^{\chi}}-\frac{\eta}{1-\chi}\right) \frac{(1-\chi) d \theta}{z \widetilde{\omega}} \theta_{z}-1$

(D.14) $R^{p} R_{z}^{p}=(1-\eta)\left(\frac{\bar{\omega}+\widetilde{\omega}}{2}\right) z+(1-\eta) \frac{\widetilde{\omega}}{2} z \widetilde{\omega}_{z}-\eta d \theta \theta_{z}$ 
In the following proposition, we state the stability condition of the log-linearized equilibrium.

Proposition 5 The log-linear equilibrium of $\left\{\widehat{\theta}_{t}, \widehat{\widetilde{\omega}}_{t},{\widehat{R^{p}}}_{t}, \widehat{z}_{t}\right\}$ defined by equations (D.8)(D.9)-(D.10)-(D.11) is stable if the following condition holds

(D.15) $\left|\frac{2 \theta d}{z(\bar{\omega}-\widetilde{\omega})}\left(\frac{1}{1-\eta}\right)\left(\frac{1}{\bar{m} \theta^{\chi}}-\frac{\eta}{1-\chi}\right)\right|<1$

This condition is sufficient.

Proof. In order to prove Proposition 5, we solve the recursive equilibrium of the credit market tightness. Introducing Equation (D.9) into Equation (D.8) gives

$$
(1-\chi) \widehat{\theta}_{t}=\mathrm{E}_{t}\left\{\frac{\bar{\omega}+\widetilde{\omega}}{\bar{\omega}-\widetilde{\omega}} \widehat{z}_{t+1}+\frac{2 d / z}{\bar{\omega}-\widetilde{\omega}} \frac{1}{(1-\eta)}\left(\frac{1-\chi}{\bar{m} \theta^{\chi}}-\eta\right) \widehat{\theta}_{t+1}\right\}
$$

The current log-deviation of the credit market tightness depends on the expected values at the next period for the technological shock and the credit market tightness. Given the autoregressive process for $z_{t}$ defined in (D.3) and assuming $\mathrm{E}_{t}\left\{\varepsilon_{t+1}\right\}=0$, we obtain

$$
\widehat{\theta}_{t}=\frac{2 \theta d}{(\bar{\omega}-\widetilde{\omega}) z}\left(\frac{1}{1-\eta}\right)\left(\frac{1}{\bar{m} \theta^{\chi}}-\frac{\eta}{1-\chi}\right) \mathrm{E}_{t}\left\{\widehat{\theta}_{t+1}\right\}+\frac{\bar{\omega}+\widetilde{\omega}}{\bar{\omega}-\widetilde{\omega}} \frac{\rho_{z}}{1-\chi} \widehat{z}_{t}
$$

This is a standard intertemporal equation for $\widehat{\theta}_{t}$ that can be solved by iterating over the future period. Let us simplify the equation as follows

$$
\widehat{\theta}_{t}=\mathbf{a} \mathrm{E}_{t}\left\{\widehat{\theta}_{t+1}\right\}+\mathbf{b} \widehat{z}_{t}
$$

The assumption $|\mathbf{a}|<1$ is sufficient to guarantee the stability of the equilibrium. We then deduce the value of the coefficient $\theta_{z}$ that satisfies

$$
\widehat{\theta}_{t}=\mathbf{a} \rho_{z} \theta_{z} \widehat{z}_{t}+\mathbf{b} \widehat{z}_{t}=\theta_{z} \times \widehat{z}_{t}=\frac{\mathbf{b}}{1-\mathbf{a} \rho_{z}} \times \widehat{z}_{t}
$$

For $\left|\mathbf{a} \rho_{z}\right|<1$, the condition $\left(1-\mathbf{a} \rho_{z}\right)>0$ is always satisfied and since $\mathbf{b}>0$, we conclude that $\theta_{z}>0$. 